\title{
Regulation of thrombospondin-1 by natural and synthetic progestins in human breast cancer cells
}

\author{
Salman M Hyder ${ }^{1,2}$, Yayun Liang ${ }^{1}$, Jianbo $W^{1}$ and Vanessa Welbern ${ }^{1}$ \\ ${ }^{1}$ Dalton Cardiovascular Research Center and ${ }^{2}$ Department of Biomedical Sciences, University of Missouri-Columbia, Columbia, \\ Missouri 65211, USA \\ (Correspondence should be addressed to S M Hyder; Email: hyders@missouri.edu)
}

\begin{abstract}
Our recent studies show that progestins induce vascular endothelial growth factor (VEGF) in breast cancer cells that express mutant p53 protein. Here, we show that natural and synthetic progestins also induce thrombospondin-1 (TSP-1) mRNA and protein in T47-D and BT-474 breast cancer cells. Antiprogestin RU-486 inhibits the induction of VEGF and TSP-1 by progestins, suggesting that this effect of progestin is mediated by the progesterone receptor (PR). Actinomycin-D, but not puromycin, also blocks progestin-dependent induction of TSP-1. A putative progestin-response element was identified in the human TSP-1 promoter, which is consistent with the hypothesis that a progestin-PR complex might directly regulate transcription of the TSP-1 gene in human cells. Conditioned medium from progestin-treated breast cancer cells stimulates endothelial cell proliferation in the absence though not in the presence of antibody to TSP-1, indicating that TSP-1 secreted by breast cancer cells could be pro-angiogenic. Since tumor cell-derived TSP-1 has the potential to promote angiogenesis in the tumor microenvironment, it could be a potential target for breast cancer therapy.
\end{abstract}

Endocrine-Related Cancer (2009) 16 809-817

\section{Introduction}

Angiogenesis is essential for rapid growth of solid tumors, because it increases vascularization of tissues adjacent to the tumor, thereby increasing the supply of nutrients to rapidly proliferating tumor cells (Folkman 1995, Bergers \& Benjamin 2003, Sid et al. 2004). This suggests that it may be possible to reduce the supply of nutrients, and thereby slow or prevent tumor growth, by inhibiting angiogenesis. To implement this strategy for cancer prevention, it is necessary to understand the molecular mechanisms of angiogenesis, and identify pro- and anti-angiogenic factors associated with specific human tumors.

Postmenopausal women are often treated with synthetic oral progestins as part of hormone replacement therapy; however, recent studies suggest that exposure to progestins increases the risk of breast cancer in these women (Ross et al. 2000, Chlebowski et al. 2003, Li et al. 2003). Our previous studies suggest that increased breast cancer risk in postmenopausal women may reflect progestin-dependent induction of vascular endothelial growth factor (VEGF), a potent angiogenic factor that stimulates breast cancer cell growth in vitro and in vivo (Hyder et al. 1998, 2001, Liang et al. 2007). In an effort to find additional hormone-dependent angiogenesis-modulating factors important to the development of breast cancers, we determined that progestins also up-regulate thrombospondin-1 (TSP-1), an extracellular matrix protein, which was the first endogenous inhibitor of angiogenesis to be identified (Good et al. 1990). Although the effect of TSP-1 on tumor progression remains somewhat controversial (Tonini et al. 2003), most reports suggest that it promotes tumor progression and metastasis in general (Kodama et al. 2001, Straume \& Akslen 2001, Wakiyama et al. 2001, Byrne et al. 2007, Yee et al. 2009). For example, TSP-1 is constitutively expressed at a high level in fast-growing aggressive MDA-MB-231 human breast cancer cells (Uray et al. 2004). However, TSP-1 may also have context- and tissue-dependent roles, and may stimulate wound 
healing, cell proliferation, and adhesion of some but not all human tumor cells (Incardona et al. 1995, DiPietro et al. 1996, Wang et al. 1996a,b, Patel et al. 1997, Tobita et al. 2002, Wang-Rodriguez et al. 2003, Poon et al. 2004, Fontana et al. 2005).

This study examines the effect of natural and synthetic progestins on expression of TSP-1 in breast tumor cells, and the effects of secreted TSP-1 on endothelial cell proliferation and angiogenesis using cell-based models.

\section{Materials and methods}

\section{Materials}

T47-D and BT-474 cells (progesterone (PR) and estrogen (ER) receptors positive), and MDA-MB-231 (PR and ER negative) breast cancer cell lines were obtained from ATCC (Manassas, VA, USA). Phenol red-free DMEM/F12, DMEM, D-PBS, and $1 \times 0.05 \%$ Trypsin-EDTA were purchased from Invitrogen Corporation and Life Technologies. Fetal bovine serum (FBS) was obtained from JRH Biosciences (Lenexa, KS, USA). Progesterone, medroxyprogesterone acetate (MPA), megestrol acetate (MGA), mifepristone (RU-486), actinomycin-D, puromycin, and TSP-1 protein were obtained from Sigma. All other synthetic progestins were obtained from Steraloids (Wilton, NH, USA). TSP-1 antibody Clone A4.1 and control IgM were obtained from Neomarkers (Fremont, CA, USA), and TSP-1 ELISA kit was from R\&D Systems, Inc (Minneapolis, MN, USA). The ELISA kit to detect bromodeoxyuridine (BrdU) incorporation in cells was from Roche Diagnostics Corporation. Premade RNA blots were purchased from Seegene, Inc. (Seoul, Korea) and contained RNA prepared from various stages of mouse mammary gland development. These blots were used for northern blot analysis as described below.

\section{Cell culture and RNA collection}

Cells were grown in $100 \times 20 \mathrm{~mm}$ tissue culture dishes in phenol red-free DMEM/F12 medium supplemented with $10 \%$ FBS. At $60 \%$ confluence, cells were washed once with PBS and incubated for $18-24 \mathrm{~h}$ in $5 \mathrm{ml}$ phenol red-free DMEM/F12 medium supplemented with 5\% charcoal-stripped serum (Hyder et al. 1998). Fresh media was added with the indicated concentrations of steroids, and cells were incubated for $6 \mathrm{~h}$. Cells were harvested and total RNA prepared as previously described (Hyder et al. 1996, 1997).

\section{Northern blot analysis}

Total RNA $(20 \mu \mathrm{g})$ was denatured for $30 \mathrm{~min}$ in $15 \mathrm{mM}$ methyl mercuric hydroxide (Alfa, Salt Lake City, UT, USA) and separated on a $1 \%$ agarose gel containing $6 \%(\mathrm{v} / \mathrm{v})$ formaldehyde. After electrophoresis, gels were stained with ethidium bromide to ensure equal loading. RNA was transferred to Duralon (Stratagene, La Jolla, CA, USA) by electroblotting. Blots were probed for 28S RNA, stripped, and reprobed for TSP-1 (Hyder et al. 1996, 1997). The TSP-1 probe was prepared by nick translation of a plasmid containing the human TSP-1 gene, kindly provided by Dr Jack Lawler (Beth Israel Deaconess Medical Center, Harvard Medical School, Boston). Blots were hybridized, washed, and visualized as previously described (Hyder et al. 1996, 1997). Results were quantified by densitometric analysis.

\section{TSP-1 ELISA assay}

Cells were plated in DME/F12+10\% FBS overnight. Cells were replated in DME/F12 without serum and incubated for $24 \mathrm{~h}$. Fresh media with or without progestin or anti-progestin was added and cells were incubated for $18 \mathrm{~h}$. Media was collected and TSP-1 quantified using a Quantakine kit from R\&D Systems, according to the manufacturer's protocol. TSP-1 values were calculated by plotting absorbance at 450 and $540 \mathrm{~nm}$. Experimental values were compared with standard values. All values were normalized to total cellular protein.

\section{Protein concentration}

Cell pellets were washed once with cold PBS and resuspended in $0.2-0.3 \mathrm{ml}$ lysis buffer $(50 \mathrm{mM}$ Tris- $\mathrm{HCl} \mathrm{pH} 8.0,150 \mathrm{mM} \mathrm{NaCl}$, and 1\% NP-40). The cell suspension was vortexed for $10 \mathrm{~s}$, incubated on ice for $30 \mathrm{~min}$, and centrifuged at $15000 \mathrm{~g}$ for $15 \mathrm{~min}$ at $4{ }^{\circ} \mathrm{C}$. The supernatant was transferred to a fresh tube and protein levels quantified by BCA assay.

\section{Transient transfection assay}

TSP-1 promoter and its deletion constructs were kindly donated by Drs Hong and Kang from the Catholic University of Korea. Cells of the size $3 \times 10^{5}$ cells/well were seeded into 6-well plates, grown to 60-70\% confluence, washed with PBS, and then incubated with DMEM/F12 medium supplemented with 5\% dextrancoated charcoal-stripped serum for 18-24 h. Cells were washed and transfected with the indicated plasmids using Superfect reagent (Qiagen), according to the manufacturer's guidelines. Cells were washed and treated with 
hormone in 5\% FBS DCC medium for 18-24 $\mathrm{h}$ and then harvested. Luciferase activity was quantified using the Dual-Luciferase Reporter Assay System (Promega) and a Sirius luminometer (Berthold Detection Systems, Huntsville, AL, USA). Renilla luciferase was expressed from pRL-CMV (Promega E2261). This plasmid was co-transfected with a consensus progesterone-responsive element (PRE)-Luc at a ratio of 1:10.

\section{Western blot analysis}

T47-D cells were grown in DMEM/F12 until they were $70 \%$ confluent. Cells were then washed with PBS and incubated for $24 \mathrm{~h}$ in DMEM/F12 supplemented with 5\% dextran-coated charcoal, after which they were washed twice with PBS and media replaced with serum-free DMEM/F12. Cells were incubated with $10 \mathrm{nM}$ progesterone ( \pm RU-486) for $18-20 \mathrm{~h}$. One group of cells was given RU-486 alone, while controls were treated with vehicle alone. Cell culture supernatant (conditioned medium) from each group was collected and protease cocktail (Active Motif, Carlsbad, CA, USA) was added. Media was then concentrated at $3000 \mathrm{~g}$ for $15 \mathrm{~min}$ using a Centricon-50 filter (Millipore Corporation, Billerica, MA, USA). From concentrated cell culture supernatants $20 \mu \mathrm{g}$ of protein were separated by NuPAGE $10 \%$ Bis-Tris Gel (Invitrogen). Electrophoresis was performed at $120 \mathrm{~V}$ for $1.5 \mathrm{~h}$ using NuPAGE MES-SDS running buffer. Separated proteins were transferred to polyvinylidene difluoride membranes (Bio-Rad Laboratories) at $35 \mathrm{~V}$ for $1.5 \mathrm{~h}$ and blots were subsequently blocked for $1 \mathrm{~h}$ in $5 \%$ nonfat dry milk in tris-buffered saline (TBS) overnight. Blots were then incubated with TSP-1 antibody (Ab-11, 1:200 diluted, from Thermo Scientific, Fremont, CA, USA) for $2 \mathrm{~h}$ at RT, washed thrice with TBS containing $0.1 \%$ Tween 20 (TBS-T) at RT, and then incubated with secondary antibody for $1 \mathrm{~h}$ at RT. Blots were finally washed seven times with TBS-T and immunoreactive bands visualized using an ECL plus detection kit (Amersham, Pharmacia Biotech).

\section{Paracrine effects of MPA-induced TSP-1 on endothelial cell proliferation}

T47-D cells were grown in $100 \mathrm{~mm}$ tissue culture dishes, in medium containing $10 \%$ FBS and allowed to reach $\sim 70-80 \%$ confluence. Cells were washed twice with PBS and treated with 5\% DCC FBS in DME/F12 for $24 \mathrm{~h}$. Cells were washed and replaced with serumfree DME/F12 containing $10 \mathrm{nM}$ MPA for $18 \mathrm{~h}$. Conditioned medium was collected, filtered through a $0.2 \mu \mathrm{m}$ membrane, and used immediately for treatment of HUVEC cells (as described below).
HUVEC cells $\left(5 \times 10^{3}\right.$ cells/well $)$ were seeded in a 96-well plate containing culture medium with FBS overnight. Media was replaced with DME/F12 containing $1 \%$ FBS overnight, after which cells were washed, conditioned media added, and incubated for $24 \mathrm{~h} \pm$ anti-TSP-1 antibody or IgM control (Liang et al. 2006). Fifteen hours prior to the end of the experiment, $100 \mu \mathrm{M}$ BrdU was added to each well. BrdU incorporation was measured by ELISA.

\section{Statistical analysis}

Values are reported as mean \pm s.E.M. Statistical analysis was carried out using ANOVA and nonparametric tests based on ranks were used as needed. Values were considered significant if $P<0.05$. The Student-Newman-Keuls multirange test was used to compare mean values. For fold-induction bar graphs and transient transfection assays, Student's $t$-test was used to compare mean values.

\section{Results}

\section{Natural and synthetic progestins induce TSP-1 in breast cancer cells}

T47-D is a well-characterized PR-positive breast cancer cell line, which is suitable for examining the effect of natural and synthetic progestins on gene expression and cellular growth. In this study, T47-D cells were cultured \pm MPA, a highly stable synthetic progestin. Initially, the kinetics of expression of TSP-1 were analyzed by northern blot analysis of total cellular RNA. The results showed that TSP-1 mRNA was induced transiently in cells treated with MPA, the highest levels being detected 3-6 $\mathrm{h}$ after the start of MPA treatment (Fig. 1A). The bar graph in Fig. 1B represents fold-induction of TSP-1 in response to progesterone, normalized to band intensity of $28 \mathrm{~S}$ RNA. There was a 4-5-fold induction of TSP-1 message in T47-D cells in response to progesterone 3-6 h after hormone treatment; induction returned to basal levels at 12-24 h. The effect of progesterone on TSP-1 transcription was dose-dependent, but showed inhibition at high concentrations of progesterone (Fig. 1C). The highest level of TSP-1 mRNA was induced by $10^{-9} \mathrm{M}$ progesterone, which is considered to be within the physiological concentration of the hormone. Actinomycin-D, which inhibits RNA transcription by RNA polymerase II, inhibited progesterone-induced expression of TSP-1 mRNA, suggesting a direct effect of activated PR on transcription (Fig. 1D). In contrast, puromycin, 

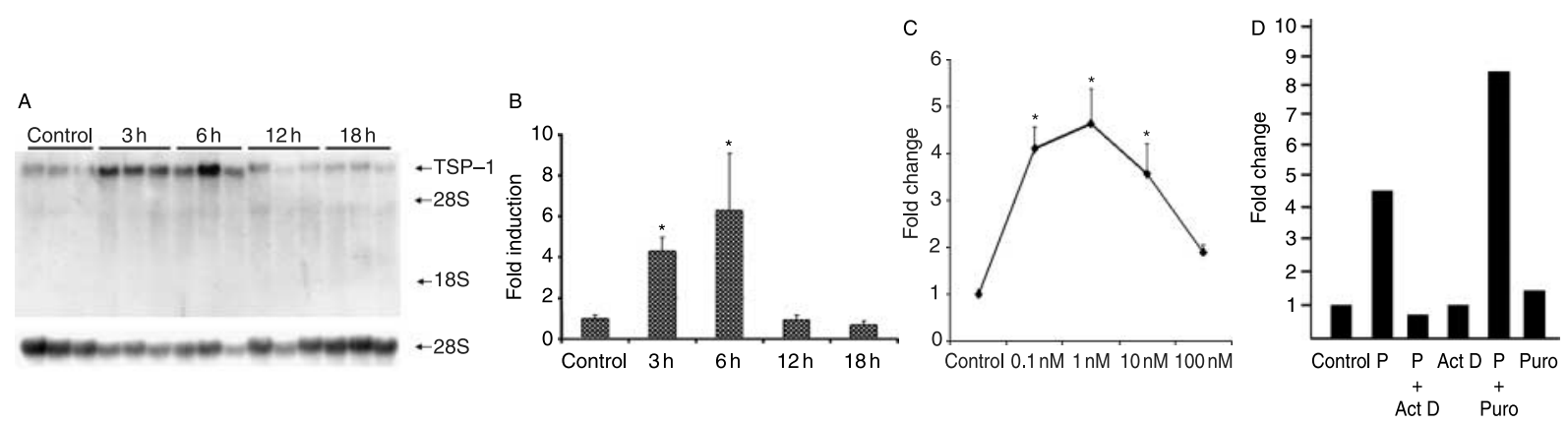

Figure 1 Northern blot analysis of TSP-1. T47-D cells were cultured and total RNA prepared and analyzed by northern blot as described in Materials and methods. Blots were probed for 28S RNA or TSP-1 as described in Materials and methods. (A) Cells were treated with $10 \mathrm{nM}$ MPA for 3, 6, 12, or $18 \mathrm{~h}$, as indicated. (B) Band intensities for TSP-1 shown in (A) were normalized with the band intensities of $28 \mathrm{~S}$ and then plotted as a bar graph of fold induction compared with controls. *Represents significantly different from control $(P<0.05$, Student's $t$-test). (C) Cells were incubated for $6 \mathrm{~h}$ with the indicated dose of progesterone. Autoradiograms were scanned and densitometric values for TSP-1 bands normalized with densitometric values for $28 \mathrm{~S}$ in each lane. Values are mean +S.E.M. ( $n=3$ per time point). (D) Cells were treated with $10 \mathrm{nM}$ progesterone for $6 \mathrm{~h}$ in the presence of actinomycin D (Act D; $2 \mu \mathrm{g} / \mathrm{ml}$ ) or puromycin (Puro; $10 \mu \mathrm{g} / \mathrm{ml}$ ), and RNA was collected for northern blot analysis. Values are the mean of two determinations.

which inhibits protein synthesis, did not inhibit progesterone-induced expression of TSP-1 mRNA.

Progesterone, MPA, MGA, norgestrel, and norethindrone all induced TSP-1 mRNA to a similar extent in T47-D cells, and the effect of these progestins $(10 \mathrm{nM})$ was in each case inhibited completely by 100 -fold excess $(1 \mu \mathrm{M})$ of RU-486, indicating that the response was mediated via the PR (Fig. 2A). To ensure that induced TSP-1 message led to synthesis and secretion of progestin dependent TSP-1 from breast cancer cells, we performed a western blot analysis of media collected following an overnight incubation of cells with progesterone. As shown in Fig. 2B, progesterone induced a threefold induction of TSP-1 in media. Further confirmation of secreted TSP-1 in response to various progestins was conducted using an ELISA kit as described below. Furthermore, TSP-1 message was also induced by progesterone in BT-474 cells that express PR (Fig. 1C), though not in a PR negative MDA-MB-231 cell line (data not shown).

The effect of progestins on expression of TSP-1 in T47-D cells was confirmed by measuring secretion of TSP-1 into the culture medium. For these experiments, cells were serum-starved and then incubated for $18 \mathrm{~h}$ in the presence of ligand $(0,1,10$, or $100 \mathrm{nM}) \pm$ a 100 fold excess of anti-hormone ( $1 \mu \mathrm{M}$ RU-486). Culture medium was then collected and assayed for TSP-1 protein by ELISA (Fig. 3A and B). These experiments confirmed that natural and synthetic progestins induce expression and secretion of TSP-1 in a PR-dependent manner in T47-D cells. Similar effects were observed in BT-474 cells (Fig. 3C).

\section{TSP-1 promoter contains a PRE}

The above results suggest that ligand-activated PR directly stimulates transcription from the TSP-1 promoter. This idea was tested by examining progesterone-dependent transcription of a series of TSP-1

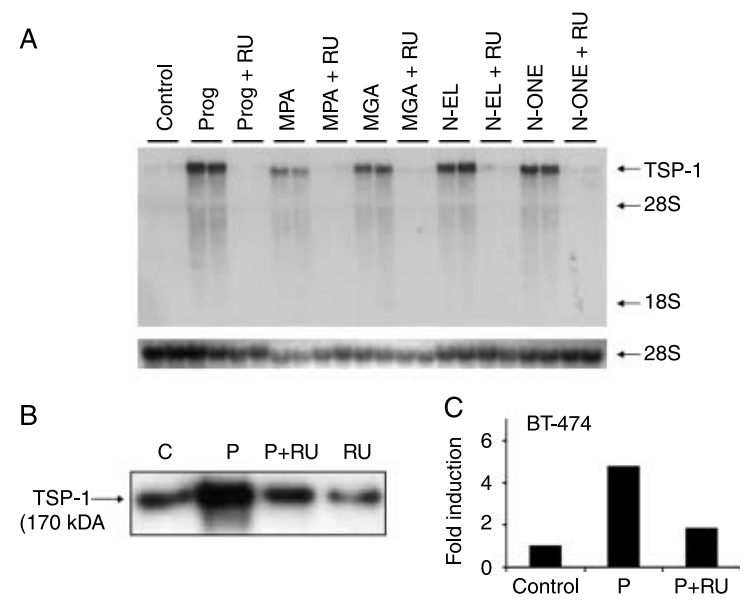

Figure 2 (A) Northern blot analysis of TSP-1. T47-D cells were cultured and total RNA prepared and analyzed by northern blot as described in Materials and methods. The blot was probed for 28S RNA or TSP-1 as described in Materials and methods. Cells were treated for $6 \mathrm{~h}$ with $10 \mathrm{nM}$ progesterone (Prog), medroxyprogesterone acetate (MPA), megestrol acetate (MGA), norgestrel (N-EL), or norethindrone (N-ONE) $\pm 1 \mu \mathrm{M}$ $\mathrm{RU}$-486. (B) Western blot analysis of serum-free media collected after treating T47-D cells with progesterone $(P)$ in the absence (C, control) and presence of RU-486 (RU). Treatment of media prior to western blot analysis is described in Materials and methods. Values represent mean of two determinations normalized to $28 \mathrm{~S}$ band intensity. (C) Northern blot analysis of TSP-1 induction by progesterone (P) in BT-474 cells. Treatment of cells and RNA analysis were as described in (A). 

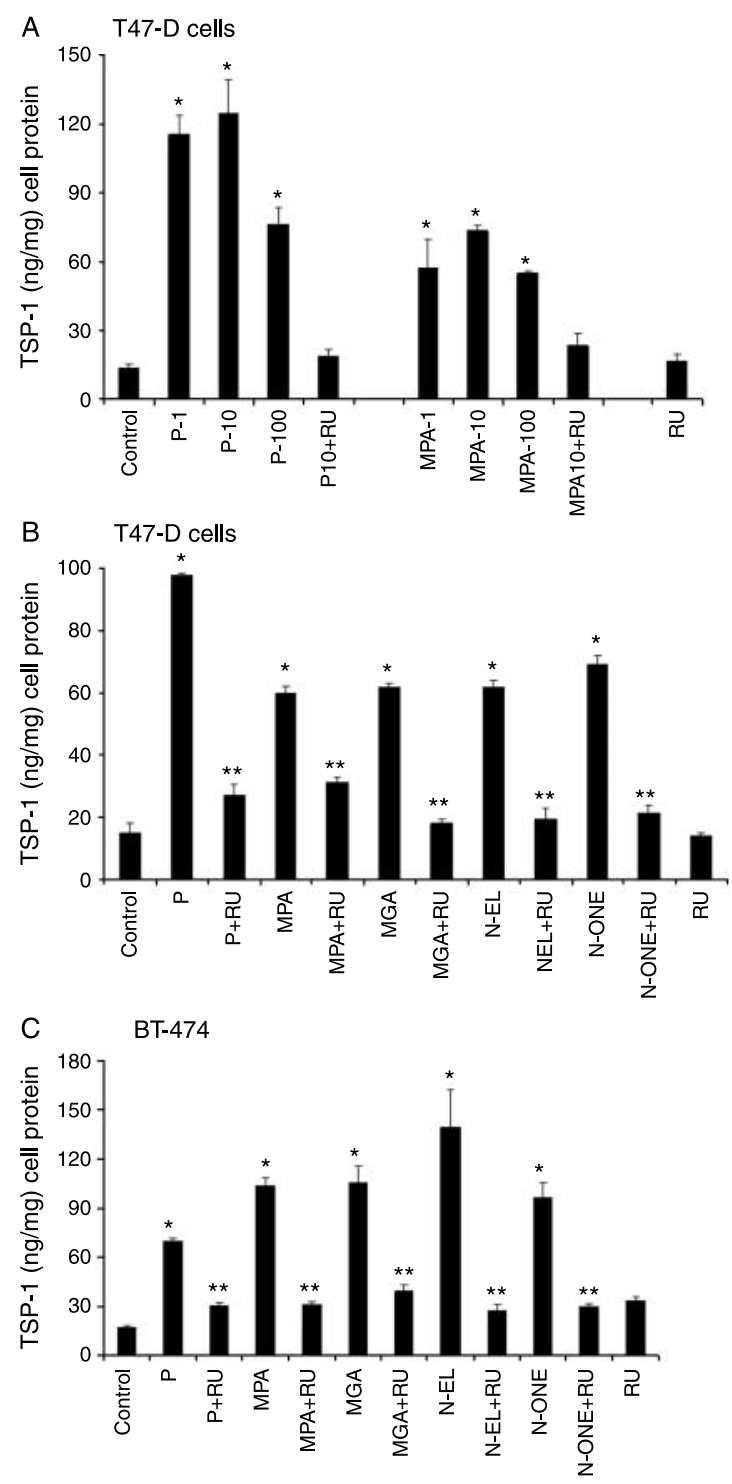

Figure 3 Quantification of secreted TSP-1. (A) T47-D cells were incubated overnight in DME/F12+5\% FBS. Fresh serum-free medium was added and cells were treated with 1,10 , or $100 \mathrm{nM}$ hormone or $10 \mathrm{nM}$ hormone and $1 \mu \mathrm{M} \mathrm{RU}-486$ for $18 \mathrm{~h}$ as indicated. Media was collected and TSP-1 quantified by ELISA. (B) Same as in (A), except cells were treated with $10 \mathrm{nM}$ of the following progestins, as indicated: MGA, megestrol acetate; $\mathrm{N}-\mathrm{EL}$, norgestrel; N-ONE, norethindrone. (C) Same as in (B), except using BT-474 cells. *Significantly different from control; ** significantly different from hormone treatment in the absence of RU-486 $(P<0.05$, ANOVA).

promoter/luciferase reporter gene constructs transfected into T47-D cells. The reporter constructs carried a luciferase reporter gene fused to a full length $(-2200$ to +754$)$ or truncated TSP-1 promoter (Fig. 4; see Materials and methods). The results show that the deletion of the region -2200 to -1733 eliminated progesterone-dependent luciferase activity in transfected T47-D cells, while expression from the intact TSP-1 promoter/luciferase construct increased approximately threefold when transfected cells were exposed to progesterone (Fig. 4).

\section{TSP-1 induces proliferation of endothelial cells}

The effect of secreted TSP-1 on cellular proliferation was also examined by incubating HUVEC cells with 'conditioned media' from MPA-treated T47-D cells and measuring DNA synthesis (BrdU assay). The results show that the conditioned media significantly stimulated the proliferation of HUVEC in the absence but not in the presence of antibody to TSP-1 (Fig. 5).

\section{Developmental regulation of TSP-1 in vivo}

The above results suggest that expression of human TSP-1 might increase in human breast exposed to physiological concentrations of progesterone or progesterone-like hormones. Therefore, we determined whether a similar scenario might exist in the mouse mammary gland. For this purpose, TSP-1 mRNA was quantified in the mammary gland of female mice at various stages of development (Fig. 6). The results show biphasic expression of TSP-1 mRNA during mouse development. As expected, TSP-1 mRNA was absent from the mammary gland of virgin mice, but its level increased during pregnancy, when progesterone is high, decreased during lactation, when progesterone is lower than during pregnancy, and increased again
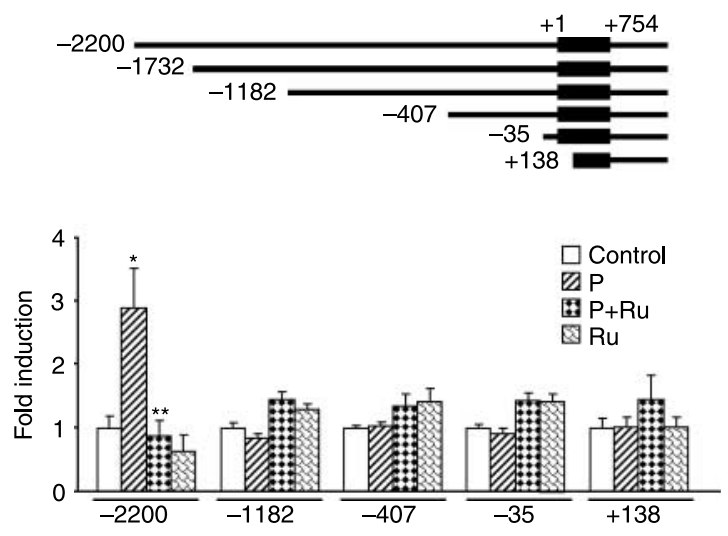

Figure 4 Transient transfection assay. Reporter gene constructs are shown schematically in the upper part of the figure. DNA sequence coordinate of the human TSP-1 promoter is indicated. Transcription start site of TSP-1 gene is indicated by +1 . Cells were treated with $10 \mathrm{nM}$ progesterone $\pm 1 \mu \mathrm{M}$ $\mathrm{RU}-486(\mathrm{RU})$ for $18 \mathrm{~h}$. Cells were harvested and luciferase activity was quantified. *Significantly different than control; ${ }^{* *}$ significantly different than progesterone treatment in the absence of RU-486 ( $P<0.05$, Student's $t$-test). 


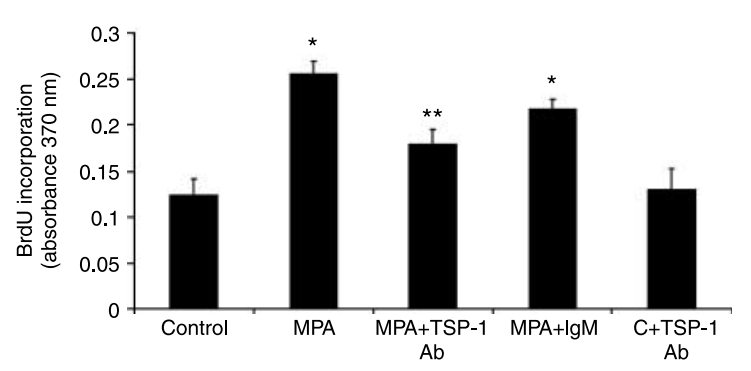

Figure 5 Effect of conditioned medium on proliferation of HUVEC cells. T47-D cells were serum-starved and then incubated in fresh media with $10 \mathrm{nM}$ MPA or vehicle alone for $18 \mathrm{~h}$. Conditioned media was collected and placed onto HUVEC cells for $21 \mathrm{~h} \pm$ TSP-1 antibody (TSP-1 Ab $1 \mu \mathrm{g} / \mathrm{ml}$ ) or nonspecific $\operatorname{lgM}(1 \mu \mathrm{g} / \mathrm{ml}$; see Materials and methods). BrdU was added to the media, and cells were incubated for an additional $3 \mathrm{~h}$. Cells were harvested and BrdU was quantified by ELISA. *Significantly different from control; ** significantly different from value shown in MPA alone group ( $P<0.05$, ANOVA).

during mammary gland involution. These results are consistent with the possibility that expression of TSP-1 mRNA is regulated by endogenous progesterone in the mouse mammary gland.

\section{Discussion}

This study examines the effect of natural and synthetic progestins on expression of TSP-1 in PR-positive breast cancer cells. Progesterone and synthetic progestins (0.1-10 nM) induced TSP-1 mRNA approximately fourfold in T47-D cells. Secreted TSP-1 protein also significantly increased in response to progesterone and progestins, and comparable effects were observed in PR-positive BT-474 human breast cancer cells. In all cases, the effects of progesterone and progestins appeared to be mediated via interaction with PR, since such effects were completely suppressed by PR antagonists or anti-progestins. These results suggest that physiological concentrations of progesterone might have comparable effects in PR-positive human breast cells. Furthermore, similar gene expression changes might occur in women exposed to synthetic progestins as oral contraceptives or hormone

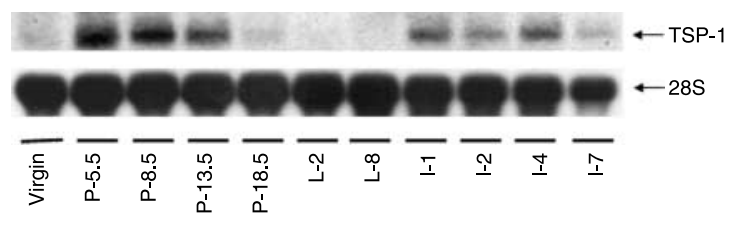

Figure 6 Expression of TSP-1 mRNA in mouse mammary gland. TSP-1 mRNA was prepared from female mice at the indicated stage of mammary gland development: virgin; pregnant $(P)$; lactating $(L)$; involuting $(\mathrm{I})$. Numbers indicate days of development. Northern blot analysis was performed for TSP-1 as described in Materials and methods. replacement therapy, and progestins may also regulate expression of TSP-1 in endometrial cells (IruelaArispe et al. 1996, Mirkin \& Archer 2004). Thus, the effects reported here are likely to be physiologically relevant for women exposed to endogenous progesterone and/or exogenous progestins.

In the present study, we observed that progestins induced TSP-1 message in a biphasic manner (Fig. 1C), i.e. while the message increased in a dose-dependent manner at lower concentrations, induction of message was lower at a higher dose. This is consistent with other reports where expression of VEGF was affected similarly by progestins (Hyder et al. 2001). It is possible that different PR isoforms affect TSP-1 gene expression differently and that the relative expression of each isoform of PR may dictate the final outcome. For example, in vitro studies show that progesterone receptor A (PRA) can reduce the level of gene expression mediated by progesterone receptor B (PRB) (Giangrande et al. 2000). Thus, it is possible that progestins may influence the level of each receptor in T47-D cells, thereby influencing the transcriptional properties of the PR complex. It is also interesting to note that on a global level progestins exert comparable effects on cell growth that are time- and dosedependent, i.e. while lower concentrations increase cell proliferation, higher doses have the opposite effect (Manni et al. 1987, Sutherland et al. 1998).

The mechanism by which progestins induce TSP-1 was addressed by promoter deletion analysis (Fig. 4). A putative PR-response element, in the region -2200 to -1733 , was identified in the promoter of the human TSP-1 gene. Deletion of this region from the TSP-1 promoter eliminated its ability to drive progesteronedependent expression of a luciferase reporter gene in T47-D cells. Additional experiments are needed to verify the nature and properties of this putative PR-response element in the TSP-1 promoter. However, since our initial studies indicate that progesterone may regulate expression of TSP-1 in the mammary gland of pregnant and lactating female mice (Fig. 6), the putative PR-response element may be evolutionarily conserved in the TSP-1 promoter.

Previous studies show that progestins also induce expression and secretion of VEGF in human breast cancer cells (Hyder et al. 1998, 2001, Liang et al. 2006, 2007). Secreted VEGF stimulates angiogenesis, thereby supporting progression of PR-positive breast tumors. Here, we also show that secreted TSP-1 stimulates proliferation of HUVEC cells (Fig. 5), supporting the idea that TSP-1 could be pro-proliferative in breast cancer since expression of TSP-1 correlates with higher risk of disease recurrence 
(Pratt et al. 1989, Wakiyama et al. 2001). Previously, TSP-1 was shown to inhibit endothelial cell proliferation (Bagavandoss \& Wilks 1990, Sengupta et al. 2004). However, these studies were carried out using high concentrations of TSP-1, e.g. Bagavandoss \& Wilks (1990) used 30-60 $\mu \mathrm{g} / \mathrm{ml}$ TSP-1, whereas Sengupta et al. (2004) used $10 \mu \mathrm{g} / \mathrm{ml}$ TSP-1 to demonstrate an inhibitory effect on endothelial cells. Our unpublished observations show that TSP-1 is inhibitory towards endothelial cells when used at or above $10 \mu \mathrm{g} / \mathrm{ml}$ in the in vitro cell proliferation assays. However, when endothelial cells are exposed to concentrations of TSP-1 below $10 \mu \mathrm{g} / \mathrm{ml}$, cellular proliferation increases, an observation concordant with previous studies (Pazouki et al. 1996, Qian et al. 1997). It should be noted that not only the concentration of TSP-1 but also its cellular environment is important in determining whether TSP-1 protein functions in a proliferative or inhibitory capacity (Sargiannidou et al. 2001). Interestingly, pro-angiogenic domains have been described in TSP1 and it is likely that TSP-1 derived from tumors is cleaved in a manner that is conducive to it being proangiogenic (Sargiannidou et al. 2001, Tonini et al. 2003). We should note however, that we were unable, using western blot analysis, to observe a cleaved product produced by T47-D cells, suggesting that the pro-angiogenic functions measured in our studies arise most likely from an angiogenic domain in full-length TSP-1. Thus, TSP-1 may stimulate angiogenesis, and may also be involved in cell migration, or cell adhesion in its native state (Sargiannidou et al. 2001). As our study also demonstrates, TSP-1 appears to be under hormonal regulation in normal mouse mammary gland where it is strongly expressed during pregnancy when the mammary gland is undergoing major developmental changes under the influence of both estrogen and progesterone. TSP-1 may be involved in various functions such as cell proliferation, migration, and adhesion during alveolar lobular growth that occurs during pregnancy. Further studies are needed to define the effects of TSP-1 in specific tissues and specific biological microenvironments.

In summary, we show that exposure to progestins induce expression of TSP-1 in PR-positive breast cells. Furthermore, TSP-1 may stimulate cell proliferation and/or angiogenesis in a context-dependent manner. These data together with our recently published findings showing that TSP-1 is also under estrogen regulation in breast cancer cells (Hyder et al. 2009) places TSP-1 in a small group of genes that are not only regulated by both estrogens and progestins, but are also involved in tumor cell proliferation.

\section{Declaration of interest}

The authors declare that there is no conflict of interest that would prejudice the impartiality of this scientific work.

\section{Funding}

This research was supported by Susan G Komen grant BCTR 0600704, by NIH grants CA-86916 and R56-86916, and by a COR grant from the College of Veterinary Medicine, University of Missouri-Columbia. S M Hyder is the Zalk Missouri Prof. of Tumor Angiogenesis.

\section{Acknowledgements}

We wish to thank Ms Constance Chiappetta and Ms Zhifang Zhu for technical assistance with parts of these studies.

\section{References}

Bagavandoss P \& Wilks JW 1990 Specific inhibition of endothelial cell proliferation by thrombospondin.

Biochemical and Biophysical Research Communications 170 867-872.

Bergers G \& Benjamin LE 2003 Tumorigenesis and the angiogenic switch. Nature Reviews. Cancer 3 401-410.

Byrne GJ, Hayden KE, McDowell G, Lang H, Kirwan CC, Tetlow L, Kumar S \& Bundred NJ 2007 Angiogenic characteristics of circulating and tumoural thrombospondin-1 in breast cancer. International Journal of Oncology 31 1127-1132.

Chlebowski RT, Hendrix SL, Langer RD, Stefanick ML, Gass M, Lane D, Rodabough RJ, Gilligan MA, Cyr MG \& Thomson CA 2003 Influence of estrogen plus progestin on breast cancer and mammography in healthy postmenopausal women: the Women's Health Initiative Randomized Trial. Journal of the American Medical Association 289 3243-3253.

DiPietro LA, Nissen NN, Gamelli RL, Koch AE, Pyle JM \& Polverini PJ 1996 Thrombospondin-1 synthesis and function in wound repair. American Journal of Pathology 148 1851-1860.

Folkman J 1995 Angiogenesis in cancer, vascular, rheumatoid and other disease. Nature Medicine 1 27-31.

Fontana A, Filleur S, Guglielmi J, Frappart L, Bruno-Bossio G, Boissier S, Cabon F \& Clezardin P 2005 Human breast tumors override the antiangiogenic effect of stromal thrombospondin-1 in vivo. International Journal of Cancer 116 686-691.

Giangrande PH, Kimbrel EA, Edwards DP \& McDonnell DP 2000 The opposing transcriptional activities of the two isoforms of the human progesterone receptor are due to differential cofactor binding. Molecular and Cellular Biology 20 3102-3115.

Good DJ, Polverini PJ, Rastinejad F, Le-Beau MM, Lemons RS, Frazier WA \& Bouck N 1990 A tumor 
suppressor-dependent inhibitor of angiogenesis is immunologically and functionally indistinguishable from a fragment of thrombospondin. PNAS 87 6624-6628.

Hyder SM, Stancel GM, Chiappetta C, Murthy L, BoettgerTong HL \& Makela S 1996 Uterine expression of vascular endothelial growth factor is increased by estradiol as well as tamoxifen. Cancer Research 56 3954-3960.

Hyder SM, Chiappetta C, Murthy L \& Stancel GM 1997 Selective inhibition of estrogen regulated genes in vivo by pure antiestrogen ICI 182,780. Cancer Research 57 2547-2549.

Hyder SM, Murthy L \& Stancel GM 1998 Progestin regulation of vascular endothelial growth factor in human breast cancer. Cancer Research 58 392-395.

Hyder SM, Chiappetta C \& Stancel GM 2001 Pharmacological and endogenous progestins induce vascular endothelial growth factor expression in human breast cancer cells. International Journal of Cancer 92 469-473.

Hyder SM, Liang Y \& Wu J 2009 Estrogen regulation of thrombospondin-1 in breast cancer cells. International Journal of Cancer [in press].

Incardona F, Lewalle JM, Morandi V, Lambert S, Legrand Y, Foidart JM \& Legrand C 1995 Thrombospondin modulates human breast adenocarcinoma cell adhesion to human vascular endothelial cells. Cancer Research 55 166-173.

Iruela-Arispe ML, Porter P, Bornstein P \& Sage EH 1996 Thrombospondin-1, an inhibitor of angiogenesis, is regulated by progesterone in the human endometrium. Journal of Clinical Investigation 97 403-412.

Kodama J, Hashimoto I, Seki N, Hongo A, Yoshinouchi M, Okuda H \& Kudo T 2001 Thrombospondin-1 and -2 messenger RNA expression in invasive cervical cancer: correlation with angiogenesis and prognosis. Clinical Cancer Research 7 2826-2831.

Li CI, Malone KE, Porter PL, Weiss NS, Tang MC, Cushing-Haugen KL \& Daling JR 2003 Relationship between long durations and different regimens of hormone therapy and risk of breast cancer. Journal of the American Medical Association 289 3254-3263.

Liang Y, Brekken RA \& Hyder SM 2006 VEGF induces proliferation of breast cancer cells and counteracts the anti-proliferative activity of anti-hormones. Endocrine Related Cancer 13 905-919.

Liang Y, Besch-Williford C, Brekken RA \& Hyder SM 2007 Progestin-dependent progression of human breast tumor xenografts: a novel model for evaluating anti-tumor therapeutics. Cancer Research 67 9929-9936.

Manni A, Badger B, Wright C, Ahmed SR \& Demers LM 1987 Effects of progestins on growth of experimental breast cancer in culture: interaction with estradiol and prolactin and involvement of the polyamine pathway. Cancer Research 47 3066-3071.

Mirkin S \& Archer DF 2004 Effects of levonorgestrel, medroxyprogesterone acetate, norethindrone, progesterone, and 17 $\beta$-estradiol on thrombospondin-1 mRNA in Ishikawa cells. Fertility and Sterility $\mathbf{8 2}$ 220-222.

Patel MK, Lymn JS, Clunn GF \& Hughes AD 1997 TSP-1 is a powerful mitogen and chemo-attractant for human vascular smooth cells. Arteriosclerosis, Thrombosis, and Vascular Biology 17 2107-2114.

Pazouki S, Pendleton N, Heerkens E, Smither RL, Moore JV \& Schor AM 1996 Biphasic effect of thrombospondin-1 (TSP-1) in the regulation of angiogenesis in human breast carcinoma. Biochemical Society Transactions 24 368S.

Poon RT, Chung KK, Cheung ST, Lau CP, Tong SW, Leung KL, Yu WC, Tuszynski GP \& Fan ST 2004 Clinical significance of TSP-1 expression in hepatocellular carcinoma. Clinical Cancer Research 10 4150-4157.

Pratt DA, Miller WR \& Dawes J 1989 Thrombospondin in malignant and non-malignant breast tissue. European Journal of Cancer \& Clinical Oncology 25 343-350.

Qian X, Wang TN, Rothman VL, Nicosia RF \& Tuszynski GP 1997 Thrombospondin-1 modulates angiogenesis in vitro by up-regulation of matrix metalloproteinase-9 in endothelial cells. Experimental Cell Research 235 403-412.

Ross RK, Paganini-Hill A, Wan PC \& Pike MC 2000 Effect of hormone replacement therapy on breast cancer risk: estrogen versus estrogen plus progestin. Journal of the National Cancer Institute 92 328-332.

Sargiannidou I, Zhou J \& Tuszynski GP 2001 The role of thrombospondin-1 in tumor progression. Experimental Biology and Medicine 226 726-733.

Sengupta K, Banerjee S, Saxena NK \& Banerjee SK 2004 Thombospondin-1 disrupts estrogen-induced endothelial cell proliferation and migration and its expression is suppressed by estradiol. Molecular Cancer Research 2 150-158.

Sid B, Sartelet H, Bellon G, El Btaouri H, Rath G, Delorme N, Haye B \& Martiny L 2004 TSP-1: a multifunctional protein implicated in the regulation of tumor growth. Critical Reviews in Oncology/ Hematology 49 245-258.

Straume O \& Akslen LA 2001 Expression of vascular endothelial growth factor, its receptors (Flt-1, KDR) and TSP-1 related to microvessel density and patient outcome in vertical growth phase melanomas. American Journal of Pathology 159 223-235.

Sutherland RL, Prall OW, Watts CK \& Musgrove EA 1998 Estrogen and progestin regulation of cell cycle progression. Journal of Mammary Gland Biology and Neoplasia 3 63-72.

Tobita K, Kijima H, Dowaki S, Oida Y, Kashiwagi H, Ishii M, Sugio Y, Sekka T, Ohtani Y, Tanaka M et al. 2002 Thrombospondin-1 expression as a prognostic predictor of pancreatic ductal carcinoma. International Journal of Oncology 21 1189-1195.

Tonini T, Rossi F \& Claudio PP 2003 Molecular basis of angiogenesis and cancer. Oncogene 22 6549-6566. 
Uray IP, Liang Y \& Hyder SM 2004 Estradiol downregulates CD36 expression in human breast cancer cells. Cancer Letters 20 101-107.

Wakiyama T, Shinohara T, Shirakusa T, John AS \& Tuszynski G 2001 The localization of thrombospondin-1 (TSP-1), cysteine-serine-valine-threonine-cysteineglycine (CSVTCG) TSP receptor, and matrix metalloproteinase-9 (MMP-9) in colorectal cancer. Histology and Histopathology 16 345-351.

Wang TN, Qian XH, Granick MS, Solomon MP, Rothman VL, Berger DH \& Tuszynski GP $1996 a$ Inhibition of breast cancer progression by an antibody to a thrombospondin-1 receptor. Surgery $120449-454$.
Wang TN, Qian XH, Granick MS, Solomon MP, Rothman VL, Berger DH \& Tuszynski GP $1996 b$ Thrombospondin-1 promotes invasive properties of human breast cancer cells. Journal of Surgical Research 63 39-43.

Wang-Rodriguez J, Urquidi V, Rivard A \& Goodison S 2003 Elevated osteopontin and thrombospondin expression identifies malignant breast carcinoma but is not indicative of metastatic status. Breast Cancer Research $\mathbf{5}$ R136-R143.

Yee KO, Connolly CM, Duquette M, Kazerounian S, Washington R \& Lawler J 2009 The effect of thrombospondin-1 on breast cancer metastasis. Breast Cancer Research and Treatment 114 85-96. 